\title{
Chantal REYNIER, Saint Paul sur les routes du monde romain. Infrastructures, logistique, itinéraires
}

Paris, Éditions du Cerf, 2009, 293 p.

\section{Anna Van den Kerchove}

\section{CpenEdition} Journals

Édition électronique

URL : http://journals.openedition.org/assr/21653

DOI : $10.4000 /$ assr.21653

ISSN : 1777-5825

Éditeur

Éditions de l'EHESS

Édition imprimée

Date de publication : 31 décembre 2009

Pagination : $75-342$

ISBN : 978-2-7132-2218-4

ISSN : 0335-5985

Référence électronique

Anna Van den Kerchove, "Chantal REYNIER, Saint Paul sur les routes du monde romain. Infrastructures, logistique, itinéraires », Archives de sciences sociales des religions [En ligne], 148 | octobre-décembre 2009, document 148-112, mis en ligne le 27 janvier 2010, consulté le 21 septembre 2020. URL : http:// journals.openedition.org/assr/21653; DOI : https://doi.org/10.4000/assr.21653

Ce document a été généré automatiquement le 21 septembre 2020.

(C) Archives de sciences sociales des religions 


\title{
Chantal REYNIER, Saint Paul sur les routes du monde romain. Infrastructures, logistique, itinéraires
}

Paris, Éditions du Cerf, 2009, 293 p.

\author{
Anna Van den Kerchove
}

\section{RÉFÉRENCE}

Chantal REYNIER, Saint Paul sur les routes du monde romain. Infrastructures, logistique, itinéraires, Paris, Éditions du Cerf, 2009, 293 p.

1 Paul est connu pour être un grand voyageur, mais les études sur ses voyages, leur déroulement, les raisons qui ont présidé au choix de telles ou telles escales ou de tels ou tels itinéraires sont rares. Chantal Reynier souhaite combler cette lacune dans l'historiographie française consacrée à Paul, avec l'idée que voyager dans l'Antiquité n'allait pas de soi. Cette étude est menée à partir des données que C. Reynier trouve dans les Actes des apôtres et dans les lettres pauliniennes et qu'elle confronte à ce que l'on sait par ailleurs des itinéraires maritimes et terrestres de l'époque, des conditions de voyage, grâce aux romans, aux ouvrages historiques et à l'archéologie. L'ouvrage est ainsi structuré en deux parties : l'une sur les itinéraires romains au $\mathrm{i}^{\mathrm{er}}$ siècle de l'ère commune, sur les conditions humaines et météorologiques des voyages, sur les ports et leurs aménagements, sur les moyens de transport, etc.; l'autre sur les différents voyages de Paul, à partir des itinéraires donnés dans les Actes, textes qui sont systématiquement cités au début de chaque chapitre de cette seconde partie.

2 L'ensemble est très descriptif : l'auteur donne beaucoup de détails, comme la largeur des voies romaines, leur nom, etc. C'est donc un livre que l'on peut lire soit du début à la fin soit en se concentrant seulement sur quelques thèmes. Trois index (lieux, auteurs 
anciens, textes bibliques) permettent au lecteur de s'y retrouver facilement, et la bibliographie, structurée par thématique, de trouver les compléments nécessaires. Dans la seconde partie, grâce à ce souci du détail, le lecteur peut suivre Paul pas à pas dans ses voyages et leurs péripéties. La confrontation des différentes sources permet aussi à l'auteur de revaloriser, par rapport à d'autres sources documentaires, le témoignage néo-testamentaire sur les conditions de voyage, en particulier le récit du transfert de Paul vers Rome (Actes 27-28,16). L'ensemble montre que Paul se représente l'espace en fonction de sa culture romaine ; comme ses contemporains, Paul préfère les voies maritimes, malgré leurs dangers. Les régions qu'il visite sont donc surtout celles ayant une façade maritime, ce qui n'empêche pas une stratégie spécifique où l'ouest du bassin méditerranéen est privilégié, en relation avec la répartition des missions entre les apôtres. L'importance des voyages ne se résume pas au temps passé sur un bateau ou sur une route, mais aussi à la manière dont ils ont influencé la mission paulinienne, géographiquement avec les escales, humainement avec la variété des populations rencontrées et spirituellement. En particulier, C. Reynier relève (p. 81) l'importance de la terminologie maritime dans certaines descriptions pauliniennes, notamment en rapport avec la persécution ou la foi. Il peut être intéressant de noter que le vocabulaire maritime est également utilisé, plus tard, par les manichéens, grands lecteurs de Paul.

3 Cet ouvrage est intéressant en ce qu'il montre une nouvelle fois combien Paul est ancré dans la culture de son époque et comment il met à profit les infrastructures romaines. Il s'adresse à un très large public; il est en effet abordable pour toute personne intéressée par la figure de Paul. De très nombreuses cartes aident le lecteur dans sa lecture.

4 Nous aimerions noter deux petites remarques critiques : page 15, C. Reynier parle d'un "témoignage postérieur à la fin du $\mathrm{I}^{\mathrm{er}}$ siècle " pour la Vie d'Apollonios de Tyane par Philostrate de Lemnos. Cette expression n'est pas très claire, laissant entendre que l'œuvre date de la fin du Ier siècle. Or, si Apollonios de Tyane a bien vécu à la fin du Ier siècle, sa vie écrite par Philostrate de Lemnos date de la fin du $\mathrm{II}^{\mathrm{e}}$ siècle. Page 57, l'auteur compare la capacité des bateaux à l'époque avec la capacité actuelle; nous ne pensons pas que cette comparaison soit pertinente, vu les différences entre les deux époques, tant du point de vue technique que démographique. 